\title{
Exportações por Intensidade Tecnológica dos Estados Brasileiros e sua Importância no Crescimento Econômico*
}

\section{Exports by Technological Intensity of Brazilian States and their Importance in Economic Growth}

\author{
Marco Aurelio Sigismondi Ahuaji Filho** \\ Augusta Pelinski Raiher***
}

\begin{abstract}
Resumo: O presente trabalho procurou analisar a importância da composição das exportações dos estados brasileiros para o crescimento econômico no período de 1989 a 2011. Com dados do site ALICEWeb, classificaram-se as exportações em níveis tecnológicos. Na sequência, utilizaram-se painéis dinâmicos (GMM - System) para identificar o efeito das exportações - total e por níveis tecnológicos - sobre o crescimento econômico. Como corolário, observou-se que as exportações em seus diversos segmentos se elevaram nos últimos anos, porém, continuam pautadas em setores menos intensivos em tecnologia. Em especial, constatou-se a importância das exportações no crescimento econômico, gerando efeitos de externalidades (no período t e $t+1$ ), especialmente das exportações mais intensivas em tecnologia.
\end{abstract}

Palavras-chave: Exportação. Tecnologia. Crescimento econômico.

\begin{abstract}
This study aimed to analyze the importance of the composition of exports of Brazilian states for economic growth from 1989 to 2011. With ALICEWeb site data, exports ranked in technological levels. In the sequence, we used dynamic panels (GMM - System) to identify effect of exports - total and by technological levels - on economic growth. As a corollary, it was observed that the exports in the various segments rose in recent years, however, remain guided in less technology-intensive sectors. In particular, there was the importance of exports in economic growth, generating effects of externalities (in period $t$ and $t+1$ ) especially in exports more intensive technology.
\end{abstract}

Keywords: Export. Technology. Economic growth.

JEL Classification: O49.

\footnotetext{
* $\quad$ Artigo derivado do trabalho vencedor no $25^{\circ}$ Prêmio Paraná de Economia, categoria Economia Pura e Aplicada, e segundo lugar no XXII Prêmio Brasil de Economia, categoria Monografia de Graduação. Além disso, este artigo faz parte do projeto "O efeito das exportações no crescimento econômico das microrregiões do Brasil: uma análise espacial com dados em painel”, financiado pelo Conselho Nacional de Desenvolvimento Científico e Tecnológico (CNPq).

** Graduado em Ciências Econômicas pela Universidade Estadual de Ponta Grossa (UEPG). E-mail: ahuaji@yahoo.com.br

*** Doutora em Economia pelo Programa de Pós-Graduação em Economia (PPGE) da Universidade Federal do Rio Grande do Sul (UFRGS). Professora do Programa de Ciências Sociais, do Programa de Pós-Graduação em Economia e do Departamento de Economia da Universidade Estadual de Ponta Grossa (UEPG). E-mail: apelinski@gmail.com
} 


\section{Introdução}

A economia brasileira contemporânea, e principalmente o período conhecido como a Nova República, foi marcada pelo fim da ditadura militar e pelos desafios de solucionar de uma vez por todas ou, pelo menos, aliviar os problemas da dívida externa, déficit público, tendo como meta principal o combate do surto inflacionário. Atrelado aos planos econômicos, a partir do final dos anos de 1980 iniciou-se reformas institucionais voltadas à inserção externa e ao papel do Estado na economia.

Para Giambiagi et al. (2011), na Nova República consolidou-se a estabilidade macroeconômica, efetuada em conjunto com reformas estruturais, com a abertura econômica e com o intenso processo de privatizações. Ademais, com a confiança internacional restabelecida e o país se beneficiando da estabilidade macroeconômica, retomou-se o crescimento das exportações exatamente num contexto em que diversas teorias abordavam a sua importância no crescimento econômico.

Contudo, essa inserção internacional não se deu de forma homogênea ao longo do espaço brasileiro. Entre os anos de 2009-2012, apenas treze estados responsabilizavam-se por mais de $96 \%$ das exportações do país, com destaque para São Paulo que detinha 25\% desse total (ALICEWEB, 2014). A literatura é bastante enfática quanto à importância das exportações para o crescimento econômico, não apenas por sua contribuição direta na geração de renda, mas por seus efeitos indiretos, oriundos dos encadeamentos que apresenta e dos impactos na produtividade que pode ocasionar.

Por isso, essa desigualdade quanto à inserção internacional dos diferentes estados do país de alguma maneira pode estar influenciando nos seus respectivos ritmos de desenvolvimento econômico. Mais do que isso, alguns autores (CRESPO-CUARESMA; WÖRZ, 2003, dentre outros) supõem que não só as exportações em si são importantes, dando destaque também para sua composição, de maneira que as indústrias mais intensivas em tecnologia possuem um maior nível de produtividade e dinamismo do que indústrias menos intensivas em tecnologia, exercendo efeitos multiplicadores superiores sobre a renda e sobre o crescimento econômico.

A partir dessa abordagem que elenca a inserção internacional como sendo importante no processo de crescimento econômico, é que se analisaram os estados brasileiros. Mas especificamente, buscou-se identificar o efeito que as exportações segmentadas por níveis tecnológicos exercem sobre o crescimento econômico desses estados, considerando o período entre 1989 a 2011.

Para isso, cinco seções foram construídas, incluindo esta. Na segunda são apresentados os elementos teóricos que norteiam esta pesquisa. Na terceira tem- 
-se a metodologia. Na sequência é testado esse efeito das exportações na economia dos estados brasileiros, findando com as considerações finais.

\section{Crescimento Econômico e Exportações: Modelo de Feder}

A abordagem ortodoxa acerca do comércio internacional defende a abertura comercial como dinamizadora do crescimento econômico. Em síntese, destaca-se que as exportações geram externalidades no mercado interno por conta dos efeitos multiplicadores do comércio internacional, fomentando a geração de emprego e renda, induzindo outros setores a promoverem tal dinâmica. Neste cenário, o processo de exportação quando iniciado em uma economia pode promover um círculo virtuoso de desenvolvimento, tornando-o sustentável no longo prazo.

Feder (1983) foi pioneiro em desenvolver explicitamente um modelo inspirado na corrente neoclássica, partindo da hipótese de que o crescimento das exportações e o crescimento do PIB estão intimamente relacionados, destacando a existência de externalidades positivas intersetoriais oriundas do setor exportador para a economia como um todo.

Seu modelo é elaborado inicialmente pela função convencional de produção, na qual o produto (Y) é função dos fatores de produção capital $(K)$ e trabalho $(L)$. Com base nessa premissa, a economia foi dividida em dois setores produtivos: o setor doméstico (D) e o setor exportador (X). As Equações (1), (2) e (3) apresentam essa formulação:

$$
\begin{gathered}
D=F\left(K_{d}(t), L_{d}(t), X(t)\right) \\
X=G\left(K_{x}(t), L_{x}(t)\right) \\
Y=X+D
\end{gathered}
$$

Feder (1983) assume ainda que a razão entre a produtividade marginal do capital $\left(G_{k} / F_{k}\right)$ e a produtividade marginal do trabalho $\left(\mathrm{G}_{1} / \mathrm{F}_{1}\right)$ desvia-se por uma unidade do fator $(\delta)$, tendo:

$$
\left(\frac{G_{k}}{F_{k}}\right)=\left(\frac{G_{l}}{F_{l}}\right)=1+\delta
$$

Considerando que existe uma relação linear entre a produtividade marginal do trabalho e a produtividade média por trabalhador, Equação (5), admite adicionalmente que a elasticidade do produto do setor doméstico em relação às exportações é constante (6).

$$
\begin{aligned}
& F_{l}=\beta\left(\frac{Y}{L}\right) \\
& F_{x}=\theta\left(\frac{D}{X}\right)
\end{aligned}
$$


De acordo com Pinheiro (1992), o modelo de Feder apresenta dois efeitos das exportações sobre o crescimento econômico. O primeiro seria um aumento da produção em virtude da realocação dos recursos do setor doméstico $(D)$ de baixa produtividade para o setor exportador $(X)$, considerado de alta produtividade $(\delta>0)$. O segundo seria a geração de externalidades positivas proporcionada pelas exportações para o restante da economia $\left(F_{x}>0\right)$. No entanto, na ausência de externalidades $(\delta=0)$ refletiria uma alocação de recursos que maximizaria a produção doméstica.

Feder (1983) destaca que as produtividades marginais dos fatores tendem a ser inferiores no setor não exportador, particularmente por dois motivos: i) pelo ambiente mais competitivo em que as empresas orientadas para a exportação operam, de tal forma que a competição induz a inovação, a adaptabilidade, a gestão eficiente dos recursos da empresa, etc; ii) as diferentes regulamentações e restrições, tais como crédito e racionamento de divisas.

Ao manipular algebricamente as equações anteriores, chega-se à formulação do trabalho empírico de Feder, na qual o crescimento do PIB é expresso por (7).

$$
\bar{Y}=\alpha\left(\frac{K}{Y}\right)+\beta\left(\frac{\dot{L}}{L}\right)+\left[\delta(1-\delta)+F_{x}\right]\left(\frac{\dot{X}}{X}\right)\left(\frac{X}{Y}\right)
$$

onde $(K / Y)$ é a acumulação de capital, $(L / L)$ é o crescimento da força de trabalho, $(X / Y)$ é a participação das exportações no PIB, $(\dot{X} / X)$ é o crescimento das exportações, $\delta(1+\delta)$ mede o efeito diferenciado da produtividade entre os dois setores da economia (exportador e não exportador) e, por fim, $F_{x}$ mede o efeito das externalidades.

Se as produtividades marginais forem iguais entre os setores $(\delta=0)$ e se não houver externalidades intersetoriais $\left(F_{x}=0\right)$, então a Equação (7) se reduz à conhecida formulação neoclássica das origens do crescimento econômico (GALIMBERTI, 2008).

É importante destacar que Feder (1983) aplicou seu modelo para uma amostra de 54 países desenvolvidos e em desenvolvimento no período de 1964 a 1973 , confirmando a hipótese de que as exportações geram externalidades positivas e são importantes para o crescimento econômico.

\subsection{Setores Exportadores com Diferentes Intensidades Tecnológicas}

Partindo dos estudos empíricos realizados por Feder (1983), Crespo-Cuaresma e Wörz (2003) refinam a hipótese do crescimento liderado pelas exportações, supondo que não só as exportações em si são importantes, mas a sua composição também é de suma relevância. Tal ideia ancora-se no argumento de que as indústrias mais intensivas em tecnologia possuem um maior potencial de produtivida- 
de, spillovers de conhecimento e tecnologia do que indústrias menos intensivas tecnologicamente.

No modelo de Crespo-Cuaresma e Wörz (2003) tem-se a mesma generalização do modelo de Feder (1983), partindo inicialmente da função neoclássica de produção $(Y=f(K, L))$ e posteriormente dividindo a economia em dois setores:exportadores $(X)$ e não exportadores $(D)$. A diferença do modelo está justamente em assumir que existem $(S)$ setores exportadores separados por níveis tecnológicos conforme a Equação (8). Dessa forma assume-se:

$$
X(t)=\sum_{i=1}^{s} X_{i}(t)
$$

onde:

$$
\begin{gathered}
D=F\left(K_{d}(t), L_{d}(t), X_{1}(t), X_{2}(t), \ldots, X_{S}(t)\right) \\
X_{i}=G_{i}\left(K_{i}(t), L_{i}(t)\right) \quad i=1, \ldots S \\
Y=D+\sum_{i=1}^{S} X_{i}
\end{gathered}
$$

Supõe ainda que as produtividades dos fatores diferem entre o setor não exportador e cada um dos setores de exportação, divididos por níveis tecnológicos pelo fator :

$$
\left(\frac{\partial G_{i} / \partial K_{i}}{\partial F / \partial K_{D}}\right)=\left(\frac{\partial G_{i} / \partial L_{i}}{\partial F / \partial L_{D}}\right)=1+\delta_{i} \quad i=1, \ldots, S
$$

onde:

$$
\begin{aligned}
& K=K_{D}+\sum_{i=1}^{S} K_{i} \\
& L=L_{D}+\sum_{i=1}^{S} L_{i}
\end{aligned}
$$

Assume a existência de uma relação linear entre a produtividade marginal do trabalho em um setor e a produtividade média por trabalhador na economia. Depois de algumas manipulações algébricas para uma especificação mais adequada do setor exportador, dividido por setores com intensidade tecnológica, chega-se a:

$$
\bar{Y}=\beta\left(\frac{K}{Y}\right)+\gamma\left(\frac{\dot{L}}{L}\right)+\sum_{i=1}^{S}\left[\psi_{i}\left(\frac{\dot{X}_{i}}{X_{i}}\right)\left(1-\frac{\sum_{i=1}^{S} X_{i}}{Y}\right)+\left(\frac{\delta_{i}}{1+\delta_{i}}\right)\left(\frac{\dot{X}_{i}}{X_{i}}\right)\left(\frac{X_{i}}{Y}\right)\right]
$$


onde $(\dot{Y} / Y)$ é o crescimento do PIB, $(K / Y)$ é a acumulação de capital, $(\dot{L} / L)$ é o crescimento da força de trabalho, $\left(X_{i} / Y\right)$ é a participação das exportações no PIB para cada setor $i,\left(\dot{X}_{l} / X_{i}\right)$ é o crescimento das exportações para cada setor $i,\left(\frac{\delta_{i}}{1+\delta_{i}}\right)$ mede o efeito diferenciado da produtividade para cada setor $i$ e, por fim, $\psi_{i}$ mede o efeito das externalidades para cada setor $i$.

Destarte, a ideia subjacente a (15) é de que regiões sejam beneficiadas por uma maior abertura comercial, com efeitos de externalidades e de produtividades que variam dependendo do tipo de exportação que se tem.

\subsubsection{Exportações e Crescimento Econômico: Evidências Empíricas}

A análise teórica acerca da relação existente entre o comércio internacional e o crescimento econômico não é recente. Desde a teoria das vantagens comparativas de Ricardo (1982) já se buscava evidenciar a importância que a inserção internacional gera para a dinâmica interna de um país. No entanto, são no mínimo ambíguos os resultados que as diferentes correntes do pensamento econômico chegaram, não havendo consenso nem sobre quais as variáveis que movem o processo de crescimento econômico e nem quais seriam as suas principais restrições. Ademais, mesmo no campo empírico, Jayme Jr. (2001) enfatiza a baixa evidência sobre o papel do comércio no desenvolvimento econômico, não sendo conclusiva a relação existente entre eles.

Essa ambiguidade nas inferências teóricas, bem como das evidências empíricas, potencialmente é o resultado direto da amplitude e da complexidade que envolve o tema. Ou seja, não se consegue incluir todos os elementos necessários, excluindo, por vezes: as instituições, as restrições do balanço de pagamento, o ambiente macroeconômico, as políticas internas, os fatores geográficos, os fundamentos microeconômicos, entre outros.

Jayme Jr. (2001) infere que naqueles trabalhos em que a análise é feita para países em geral, a identificação da relação entre o crescimento econômico e a inserção internacional não é tão clara. Contudo, quando a análise recai para países específicos, os resultados são mais conclusivos, especialmente por considerar características particulares como as variáveis institucionais ou os padrões históricos existentes.

Como exemplo, cita-se Balassa (1978), o qual faz essa distinção analisando alguns países que estabeleceram uma base industrial, separando-os por estratégias adotadas. O autor testou a hipótese de que países que privilegiaram políticas voltadas para a expansão das exportações tenderam a ter um melhor desempenho econômico do que os países que adotaram a estratégia de substituição das importações. Dessa forma, com uma análise mais específica, considerando estratégias distintas tomadas por diferentes países, o autor encontrou evidências acerca 
de benefícios para os que optaram por políticas orientadas para as exportações em detrimento dos que privilegiaram as políticas voltadas para a substituição das importações.

Nas suas argumentações, ao efetivar ações voltadas para a fomentação das exportações, criam-se incentivos semelhantes para a produção voltada para o mercado doméstico, alocando os recursos de acordo com a vantagem comparativa existente. Dessa forma, a capacidade instalada é utilizada de forma eficiente e as economias de escala são exploradas, gerando melhorias tecnológicas em resposta à concorrência internacional. Além disso, tem-se um incremento de renda com custos menores em termos de investimento efetuado. Logo, uma orientação voltada para o comércio internacional apresenta-se como um importante fator na diferenciação no crescimento entre países. (BALASSA, 1978).

Para Frankel e Romer (1999), a complexidade de mensurar empiricamente a relação entre o comércio internacional e renda é que a participação nas relações comerciais externas de um determinado país não é determinada exogenamente. Nesse contexto e servindo como experimento natural para identificar os efeitos do comércio, os autores utilizaram variáveis instrumentais com características geográficas não correlacionadas com a renda em uma amostra de 150 países. Deram ênfase nas variáveis distância entre os parceiros e seus tamanhos, superando o problema econométrico da endogeneidade. Pelos seus resultados, existe uma relação positiva e significativa não só entre o comércio internacional e a renda, como também com o comércio interno, ressaltando que esta relação se mantém mesmo quando os autores alteram o número de países da amostra e empregam outras especificações.

Igualmente e adotando a metodologia do trabalho de Frankel e Romer (1999) para diferentes períodos de tempo, Irwin e Terviö (2002) chegaram a resultados similares, confirmando a relação positiva entre o comércio e a renda, em que apenas no período entre guerras os autores não evidenciaram tal relação.

No entanto, nem sempre a contribuição do comércio para o desenvolvimento é tão direta. Perobelli e Haddad (2006) afirmam que o resultado final está intimamente ligado com a natureza do setor exportador de cada região, dependendo da capacidade de distribuição de seus benefícios, bem como os linkages entre os demais setores da economia. Porém, participar simplesmente do comércio internacional não garante necessariamente o êxito econômico.

Destarte, o estudo empírico de Crespo-Cuaresma e Wörz (2003) demonstrou um pouco dessa diferenciação de resultados dada a natureza do produto exportado. Os autores classificaram as exportações por intensidade tecnológica em uma amostra com 45 países no período de 1981 a 1997, identificando que os países em desenvolvimento foram beneficiados por uma maior abertura comercial, principalmente através de uma melhor alocação dos recursos, resultado direto dessa 
exposição ao comércio internacional. Contudo, não foram encontrados spillovers e outras externalidades positivas para o setor doméstico da economia.

Ao mesmo tempo, o diferencial de produtividade não pode ser observado em todos os níveis de exportações por intensidade tecnológica, apresentando diferenças significativas entre eles, ou seja, o setor mais intensivo em tecnologia e o setor de produtos não manufaturados são caracterizados pela alta produtividade, enquanto o setor de baixa intensidade tecnológica apresentou uma produtividade significativamente menor. Em síntese, Crespo-Cuaresma e Wörz (2003, p. 9) destacam: "We would conclude that the evidence in this paper supports the view that restructuring towards more technology intensive export patterns is crucial for a country's long term growth prospects". Além disso, os autores estimaram o seu modelo separando os países pertencentes e não pertencentes à Organização para a Cooperação e Desenvolvimento Econômico (OCDE) e ambos os resultados apresentaram resultados diferentes, isto é, os produtos de alta tecnologia para os países pertencentes à $\mathrm{OCDE}$ foram não significativos e, para os países não pertencentes à OCDE, os resultados foram significativos.

Galimberti (2008), analisando o Brasil por um modelo derivado dos trabalhos de Feder (1983) e de Crespo-Cuaresma e Wörz (2003), observou a existência de uma relação positiva de longo prazo entre as exportações de produtos tecnológicos e a sua diversificação no crescimento. Já no curto prazo, somente as variações dos fatores capital/trabalho e as exportações de outros produtos são significativos e afetam a produção por trabalhador na economia. Por fim, o autor ressalta que os países com as maiores taxas de crescimento econômico possuem uma estrutura produtiva pautada em setores de alta tecnologia, relativamente maiores que o Brasil.

Herzer e Nowak-Lehmann (2004) analisaram a economia do Chile no período de 1962-2001 sob a hipótese de que as diversificações das exportações estão ligadas ao crescimento econômico pelo efeito das externalidades. Os autores confirmaram a hipótese de que a diversificação das exportações exerce efeitos positivos no crescimento econômico. Mais do que isso, ressaltam que a orientação dos outros setores para exportação é mais importante do que um aumento da participação das exportações industriais no total da pauta exportadora.

Ibrahim (2002), investigando os países asiáticos, encontrou uma relação positiva entre a taxa de crescimento econômico e a taxa de crescimento do setor exportador, bem como entre a taxa de crescimento econômico e as externalidades geradas pelo setor exportador. Cândido e Lima (2010) também analisaram as economias asiáticas no período de 1995-2005 e reconheceram como relevantes outros fatores (como o ambiente institucional, regulatório e de inovação) na promoção do crescimento econômico, incluindo-os na identificação e importância para a inserção externa desses países. Como corolário, da mesma forma que Ibrahim 
(2002), Cândido e Lima (2010) identificaram uma atuação positiva do comércio internacional no crescimento econômico dos países pesquisados.

Numa abrangência mais local, Soukiazis e Antunes (2011) observaram o processo de convergência econômica entre as regiões de Portugal, buscando evidências acerca da influência do comércio exterior nesta dinâmica. Os resultados mostraram um efeito significativo da inserção internacional no crescimento regional, contribuindo para um processo de convergência, gerando ainda externalidades em áreas mais competitivas e mais abertas, reforçando a visão de que o comércio exterior é essencial para um crescimento regional mais elevado.

Partindo do modelo original de Feder (1983), Galimberti e Caldart (2010) analisaram uma amostra com 22 municípios do estado do Rio Grande do Sul, e os resultados indicaram a importância das exportações no crescimento econômico através do diferencial de produtividade existente entre o setor não exportador e o setor exportador, porém, o efeito das externalidades não se apresentou como significativo para a região pesquisada. Diante do exposto, os autores consideram importantes políticas econômicas que incentivam as exportações com o objetivo de promover o crescimento econômico no âmbito municipal.

É importante ressaltar a existência de trabalhos como o de Ramos (2007), que alegam a possibilidade de regiões poderem incorrer em déficit comerciais sem impactar fortemente em suas economias. A justificativa paira na possibilidade desses déficit comerciais regionais serem contornados pelo fluxo de capital oriundo do governo central, contornando o problema sem causar danos significativos para a economia local. Porém, as evidências apresentadas por Soukiazis e Antunes (2011) rebatem parcialmente esses argumentos, na medida em que os autores demonstraram os potenciais ganhos de externalidades gerados quando as regiões conseguem estabelecer-se no mercado internacional. Ademais, os autores inferem que quando uma região apresenta déficit regionais externos, reflete a falta de competitividade econômica que possuem, limitando o crescimento econômico local. Neste sentido, a competitividade do comércio regional torna-se importante para a dinâmica econômica local, impulsionando, consequentemente, os resultados nacionais.

Enfim, embora ainda ambíguos no que diz respeito aos resultados gerais acerca da importância da inserção externa na dinâmica econômica (conforme destacado por JAYME JR., 2001), os trabalhos apresentados nesta seção demonstram que, ao fazer análises específicas, com delimitações e inclusões de elementos relevantes da região que está se analisando, é possível identificar um efeito positivo das exportações no crescimento econômico. No Quadro 1, resumem-se esses estudos empíricos com os métodos utilizados, as variáveis incluídas, a delimitação do espaço e os principais resultados obtidos. 
Quadro 1 - Resumo dos Estudos Empíricos

\begin{tabular}{|c|c|c|c|}
\hline \multirow[b]{2}{*}{ Autor } & \multirow[b]{2}{*}{ Amostras e Métodos } & \multicolumn{2}{|r|}{ Variáveis } \\
\hline & & $\begin{array}{c}\text { Dependen- } \\
\text { te }\end{array}$ & Independente \\
\hline $\begin{array}{c}\text { Balassa } \\
(1978)\end{array}$ & \begin{tabular}{|}
11 Países em Desen- \\
volvimento (1960- \\
1973) \\
Cross-section \\
(Coeficiente de \\
Correlação Spearman, \\
MQO e Função \\
Produção) \\
\end{tabular} & $\begin{array}{l}\text { Crescimento } \\
\text { Real do PNB }\end{array}$ & $\begin{array}{l}\text { Crescimento Real das Exportações } \\
(+) \text {; Força de Trabalho }(+) \text { e Inves- } \\
\text { timento/ Produtividade }(+) .\end{array}$ \\
\hline $\begin{array}{l}\text { Feder } \\
(1983)\end{array}$ & $\begin{array}{c}54 \text { Países Desenvolvi- } \\
\text { dos e em Desenvolvi- } \\
\text { mento (1964-1973) } \\
\text { Cross-section (MQO) }\end{array}$ & $\begin{array}{l}\text { Taxa de Cres- } \\
\text { cimento do } \\
\text { PIB }\end{array}$ & $\begin{array}{c}\text { Participação dos Investimentos } \\
\text { no PIB }(+) ; \text { Taxa de Crescimento } \\
\text { da População }(+) \text {; Diferencial de } \\
\text { Produtividade das Exportações (+) } \\
\text { e Efeito Externalidades das Expor- } \\
\text { tações }(+) .\end{array}$ \\
\hline $\begin{array}{l}\text { Frankel } \\
\text { e Romer } \\
\text { (1999) }\end{array}$ & $\begin{array}{c}150 \text { países (1985) } \\
\text { Cross-country (MQO, } \\
\text { Modelo Gravitacional } \\
\text { e Variáveis Instrumen- } \\
\text { tais) }\end{array}$ & $\begin{array}{c}\text { Renda } \\
\text { (per capita) }\end{array}$ & $\begin{array}{l}\text { Modelo Gravitacional (Distância } \\
\text { entre Países i e j (-); População do } \\
\text { País i (-); População do País j (+); } \\
\text { Tamanho do País i (-); Tamanho do } \\
\text { País j (-); Ausência de Litoral (-)); } \\
\text { MQO (Participação Comercial (+); } \\
\text { População (+); Tamanho do País } \\
\text { (-)); Variáveis Instrumentais (Parti- } \\
\text { cipação Comercial (+); População } \\
\text { (+) e Tamanho do País (+)). }\end{array}$ \\
\hline $\begin{array}{l}\text { Irwin e } \\
\text { Terviö } \\
(2002)\end{array}$ & $\begin{array}{c}\text { Períodos Pré-primeira } \\
\text { Guerra Mundial, entre } \\
\text { Guerras e Pós-segunda } \\
\text { Guerra Mundial } \\
\text { Cross-country (MQO, } \\
\text { Modelo Gravitacional } \\
\text { e Variáveis Instrumen- } \\
\text { tais) }\end{array}$ & $\begin{array}{l}\text { Participação } \\
\text { Comercial } \\
\text { Bilateral } \\
\text { Renda (per } \\
\text { capita) }\end{array}$ & $\begin{array}{l}\text { Modelo Gravitacional (Distância } \\
\text { entre Países i e j (-); População do } \\
\text { País i (-); População do País j }(-/+) \text {; } \\
\text { Tamanho do País i (-/+); Tamanho } \\
\text { do País j ( }(-+) \text {; Ausência de Litoral } \\
\text { (-/+)) Fronteira (+)); MQO (Parti- } \\
\text { cipação Comercial (+); População } \\
\text { (+); Tamanho do País (+)); Variá- } \\
\text { veis Instrumentais (Participação } \\
\text { Comercial (+); População (+) e Ta- - } \\
\text { manho do País (ns)). Obs: algumas } \\
\text { variáveis apresentaram resultados } \\
\text { bastante heterogêneos, variando } \\
\text { entre positivo e negativo. }\end{array}$ \\
\hline
\end{tabular}

continua... 
continuação...

\begin{tabular}{|c|c|c|c|}
\hline \multirow[b]{2}{*}{ Autor } & \multirow[b]{2}{*}{ Amostras e Métodos } & \multicolumn{2}{|r|}{ Variáveis } \\
\hline & & $\begin{array}{c}\text { Dependen- } \\
\text { te }\end{array}$ & Independente \\
\hline $\begin{array}{l}\text { Ibrahim } \\
(2002)\end{array}$ & $\begin{array}{l}6 \text { Países Asiáticos } \\
\text { (1974-1993) } \\
\text { Séries Temporais (Pro- } \\
\text { cessos Estocásticos } \\
\text { Estacionários) }\end{array}$ & $\begin{array}{c}\text { Taxa de Cres- } \\
\text { cimento do } \\
\text { PIB }\end{array}$ & $\begin{array}{l}\text { Participação dos Investimentos no } \\
\text { PIB (+); Taxa de Crescimento da } \\
\text { População (+); Participação da } \\
\text { Taxa de Crescimento das Exporta- } \\
\text { ções no PIB (+) e Efeito Externali- } \\
\text { dades das Exportações }(+) .\end{array}$ \\
\hline $\begin{array}{l}\text { Crespo- } \\
\text { Cuaresma } \\
\text { e Wörz } \\
(2003)\end{array}$ & $\begin{array}{l}45 \text { Países participantes } \\
\text { e não participantes da } \\
\text { OCDE (1981-1997) } \\
\text { Dados em Painel } \\
\text { (EC2SLS) }\end{array}$ & $\begin{array}{c}\text { Taxa de Cres- } \\
\text { cimento do } \\
\text { PIB }\end{array}$ & $\begin{array}{l}\text { Participação dos Investimentos no } \\
\text { PIB (+); Taxa de Crescimento da } \\
\text { População (+); Participação das } \\
\text { Exportações de Produtos Não Ma- } \\
\text { nufaturados (+); Participação das } \\
\text { Exportações de Produtos de Baixa } \\
\text { Tecnologia (-); Participação das Ex- } \\
\text { portações de Alta Tecnologia (+); } \\
\text { Externalidades das Exportações de } \\
\text { Produtos Não Manufaturados (-); } \\
\text { Externalidades das Exportações de } \\
\text { Produtos de Baixa Tecnologia (ns) e } \\
\text { Externalidades das Exportações de } \\
\text { Produtos de Alta Tecnologia (ns). }\end{array}$ \\
\hline $\begin{array}{l}\text { Herzer e } \\
\text { Nowak- } \\
\text { Lehmann } \\
\text { (2004) }\end{array}$ & $\begin{array}{c}\text { Chile (1962-2001) } \\
\text { Séries Temporais } \\
\text { (DOLS) }\end{array}$ & PIB Real & $\begin{array}{l}\text { Estoque de Capital (+); Taxa dos } \\
\text { Trabalhadores (+); Exportação de } \\
\text { Diversos Setores (+) e Proporção } \\
\text { de Manufaturados Exportados em } \\
\text { relação às Exportações Totais }(+) .\end{array}$ \\
\hline $\begin{array}{l}\text { Galimber- } \\
\text { ti (2008) }\end{array}$ & $\begin{array}{c}\text { Brasil (1989-2005) } \\
\text { Séries Temporais } \\
\text { (MQO) }\end{array}$ & $\begin{array}{c}\text { PIB (per ca- } \\
\text { pita) }\end{array}$ & $\begin{array}{l}\text { Capital per capita (+); Setor Expor- } \\
\text { tador de Alta Tecnologia per capita } \\
\text { (-); Setor Exportador de Outros } \\
\text { Produtos per capita (+); Índice de } \\
\text { Diversificação Horizontal e Vertical } \\
\text { das Exportações (ns). }\end{array}$ \\
\hline $\begin{array}{l}\text { Galim- } \\
\text { berti e } \\
\text { Caldart } \\
(2010)\end{array}$ & $\begin{array}{l}22 \text { Municípios de Co- } \\
\text { rede Serra - RS } \\
\text { Séries Temporais } \\
\text { (MQO) }\end{array}$ & PIB & $\begin{array}{c}\text { Taxa de Crescimento do Consumo } \\
\text { de Energia Elétrica Industrial (+); } \\
\text { Taxa de Crescimento de Empregos } \\
\text { Formais (+); Diferencial de } \\
\text { Produtividade das Exportações } \\
\text { (+) e Efeito Externalidades das } \\
\text { Exportações (-). }\end{array}$ \\
\hline
\end{tabular}

continua... 
conclusão.

\begin{tabular}{|c|c|c|c|}
\hline \multirow[b]{2}{*}{ Autor } & \multirow[b]{2}{*}{ Amostras e Métodos } & \multicolumn{2}{|r|}{ Variáveis } \\
\hline & & $\begin{array}{c}\text { Dependen- } \\
\text { te }\end{array}$ & Independente \\
\hline $\begin{array}{l}\text { Cândido } \\
\text { e Lima } \\
\text { (2010) }\end{array}$ & $\begin{array}{l}\text { Países Asiáticos (1995- } \\
\text { 2005) } \\
\text { Dados em Painel } \\
\text { (Efeitos Fixos, Efeitos } \\
\text { Aleatórios e Variáveis } \\
\text { Instrumentais) }\end{array}$ & $\begin{array}{l}\text { Crescimento } \\
\text { do PIB }\end{array}$ & $\begin{array}{l}\text { Taxa de Crescimento Anual das Ex- } \\
\text { portações (+); Volume de Comér- } \\
\text { cio (+); Poupança (ns); Câmbio } \\
\text { (ns); Inflação (-); Formação Bruta } \\
\text { de Capital Fixo (+); Investimento } \\
\text { Direto Externo (ns); Reservas (ns); } \\
\text { Investimentos Governamentais } \\
\text { (ns); Educação (ns) e Crescimento } \\
\text { da Força de Trabalho (+). }\end{array}$ \\
\hline $\begin{array}{l}\text { Soukiazis } \\
\text { e Antunes } \\
\text { (2011) }\end{array}$ & $\begin{array}{c}28 \text { Regiões de Portugal } \\
\text { (1996-2005) } \\
\text { Painel Dinâmico } \\
\text { (GMM) }\end{array}$ & $\begin{array}{l}\text { Crescimento } \\
\text { do PIB (per } \\
\text { capita) }\end{array}$ & $\begin{array}{c}\text { Taxa de Crescimento da População } \\
(+) \text {; Taxa do Nível de Escolarida- } \\
\text { de (+); Indicadores Alternativos } \\
\text { do Comércio Exterior (Balança } \\
\text { Comercial (+), Comércio de Bens } \\
\text { com a União Europeia (+), Grau } \\
\text { de Abertura com os Países Fora } \\
\text { da União Europeia (+), Proporção } \\
\text { das Exportações com os Países da } \\
\text { União Europeia (+), Proporção } \\
\text { das Exportações com o Resto do } \\
\text { Mundo (+) e Taxa de Crescimento } \\
\text { das Exportações para os Países Não } \\
\text { Membros da União Europeia (+)). }\end{array}$ \\
\hline
\end{tabular}

Fonte: Elaboração própria.

Nota: (+), (-), (ns) denotam, respectivamente, sinais e os resultados obtidos das variáveis de controle: positivo, negativo e não significativo.

\section{Metodologia}

Conforme as argumentações expostas na seção anterior, existem evidências sobre o efeito das exportações na dinâmica econômica de uma região. Como no Brasil a distribuição do crescimento econômico entre os estados é bastante desigual, buscou-se identificar se a inserção no comércio internacional não seria um fator importante neste processo.

Para isso, coletaram-se dados acerca das exportações no Sistema de Análise das Informações de Comércio Exterior via Web (ALICEWEB), para o período de 1989 a 2012. Ao invés de se usar dados anuais, optou-se pelas médias anuais, considerando cinco períodos de quatro anos e o último período de três anos (1989 a 1992; 1993 a 1996; 1997 a 2000; 2001 a 2004; 2005 a 2008 e 2009 a 2011). Tal tratamento foi utilizado no intuito de evitar distorções pontuais, que não necessaria- 
mente mostram a tendência real das exportações em cada estado. ${ }^{1} \mathrm{Na}$ estimativa econométrica, os dados utilizados foram até 2011 pela ausência de informações do PIB para 2012.

Ademais, como a literatura argumenta contribuições díspares quando considerados os diferentes níveis tecnológicos das exportações, então, subdividiram-se as contribuições em intensidades tecnológicas, seguindo a metodologia utilizada por Furtado e Carvalho (2005): alta intensidade tecnológica (setores aeroespacial; farmacêutico; informática; eletrônica e telecomunicações); média alta intensidade tecnológica (setores de material elétrico; veículos automotores; química, excluído o setor farmacêutico; ferroviário e de equipamentos de transporte; máquinas e equipamentos); média baixa intensidade tecnológica (setores de construção naval; borracha e produtos plásticos; coque, produtos refinados de petróleo e de combustíveis nucleares; outros produtos não metálicos; metalurgia básica e produtos metálicos); baixa intensidade tecnológica (outros setores e de reciclagem; madeira, papel e celulose; editorial e gráfica; alimentos, bebidas e fumo; têxtil e de confecção, couro e calçados); produtos não industriais (animais vivos; plantas vivas e produtos de floricultura; frutas, cascas de cítricos e melões; cereais; produtos in natura; objetos de arte, de coleções e antiguidades; transações especiais etc.).

Depois de organizados os dados, fez-se uma análise acerca da evolução das exportações por intensidade tecnológica nos estados brasileiros, findando com as estimações econométricas, as quais serão detalhadas na subseção que segue.

\subsection{Relações entre o Crescimento Econômico e as Exportações dos Estados Brasileiros: Aspectos Metodológicos}

Nos últimos anos, estudos procuraram mostrar a relação existente entre o crescimento da produção e o crescimento das exportações. Feder (1983), orientado pelo pensamento neoclássico, elabora um modelo formal em que o nível de produtividade é maior no setor exportador em alusão ao setor não exportador, proporcionando externalidades positivas ao setor menos produtivo. Deste modo, o crescimento pode ser gerado não apenas pelo aumento dos fatores de produção, mas também pela realocação de recursos do setor não exportador (menos eficiente) para o setor exportador (mais eficiente), conforme evidenciado em (7).

1 Em determinados anos, grande parte dos estados não obtiveram participação nas exportações em setores classificados conforme a metodologia de Furtado e Carvalho (2005), impossibilitando o cálculo da variação em relação ao ano anterior na construção das variáveis externalidades e diferencial da produtividade das exportações segundo a metodologia de Crespo-Cuaresma e Wörz (2003). Por isso, utilizaram-se médias de períodos. A opção por médias de quatro anos visou tornar homogêneo o número de anos em cada período, ficando apenas o último intervalo com três anos. 
Por outro lado, Crespo-Cuaresma e Wörz (2003) refinaram o modelo de Feder (1983) supondo que não só as exportações em si são importantes, mas também a sua composição, diferenciada por intensidade tecnológica. Dessa forma, parte-se do pressuposto de que as indústrias de maior nível tecnológico possuem um potencial elevado de produtividade, spillovers de conhecimento e tecnologia em relação às indústrias de menor nível tecnológico.

O modelo dos autores apresenta a mesma generalização do modelo de Feder (1983), sendo elaborado inicialmente a partir da função neoclássica de produção, separando o setor mais eficiente (exportador) do setor menos eficiente (não exportador). Além disso, o setor mais eficiente e, portanto, com a maior produtividade, foi dividido em subsetores: manufaturas de alta tecnologia, manufaturas de baixa tecnologia e por último, exportação de não manufaturados, conforme apresentado em (15).

Esses dois modelos, de Feder (1983) e Crespo-Cuaresma e Wörz (2003) serão testados para os estados brasileiros.

\subsubsection{Dados, Fontes e Modelos Empíricos}

Inicialmente estimou-se o modelo original de Feder (1983), visando identificar se as exportações como um todo exercem algum efeito - via externalidades e/ou produtividade - sobre a taxa de crescimento da economia de cada estado brasileiro (Equação 7).

Na sequência, com o intuito de verificar o efeito que as exportações subdivididas em níveis tecnológicos apresentam no crescimento econômico, estimou-se o modelo de Crespo-Cuaresma e Wörz (2003), conforme a Equação (15). A variável dependente considerada em ambas as estimativas (Feder; Crespo-Cuaresma e Wörz) foi a taxa de crescimento do produto interno bruto ( $\triangle \mathrm{PIB})$ dos estados brasileiros. Para a elaboração dessa variável foram utilizados dados do Ipeadata referentes ao PIB estadual a preços constantes do ano 2000.

Como variáveis explicativas, teve-se: taxa de crescimento do capital físico, taxa de crescimento da população, diferencial de produtividade (setor exportador versus setor doméstico) e externalidades do setor exportador. O que difere a estimativa que foi feita para (7) da (15), é que na primeira consideraram-se apenas as externalidades e o diferencial da produtividade das exportações como um todo, não a subdividindo em setores de intensidades tecnológicas e, na segunda, consideraram-se tais efeitos decompondo as exportações por intensidades tecnológicas.

Portanto, para a aplicação empírica do modelo de Feder (7), as variáveis explicativas usadas foram: taxa de crescimento do capital físico $(\triangle \mathrm{ENE})$, cuja proxy utilizada foi o consumo de energia elétrica industrial² (IPEADATA, 2014; BRASIL,

2 Utilizou-se como proxy para o capital físico o consumo de energia elétrica industrial, conforme 
2011); taxa de crescimento da população ( $\Delta$ POP) (IPEADATA, 2014); diferencial de produtividade das exportações (PRD) calculada por $\left(\frac{\Delta X_{i t}}{X_{i t}} \frac{X_{i t}}{Y_{i t}}\right)$; externalidades das exportações (EXT), tendo como fórmula $\left(\frac{\Delta x_{i t}}{x_{i t}}\left(1-\frac{\sum x_{i t}}{Y_{i t}}\right)\right)$.

Para o modelo de Crespo-Cuaresma e Wörz (15), as variáveis explicativas usadas foram: taxa de crescimento do capital físico $(\triangle \mathrm{ENE})$; taxa de crescimento da população $(\triangle \mathrm{POP})$; diferencial de produtividade do setor de alta tecnologia $\left(\mathrm{PRD}_{\text {alta }}\right)$, somando-se os valores dos setores de alta e média alta intensidade tecnológica; ${ }^{3}$ diferencial de produtividade do setor de baixa tecnologia $\left(\mathrm{PRD}_{\text {baixa }}\right)$, em que se agregaram os valores dos setores de média baixa e baixa intensidade tecnológica; diferencial de produtividade do setor de produtos não industriais $\left(\mathrm{PRD}_{\text {ñind }}\right)$; externalidades do setor de alta tecnologia $\left(\mathrm{EXT}_{\text {alta }}\right)$; externalidades do setor de baixa tecnologia $\left(\mathrm{EXT}_{\text {baixa }}\right)$; e externalidades do setor de produtos não industriais $\left(\mathrm{EXT}_{\text {ñind }}\right)$.

Tanto na estimativa do modelo de Feder como na de Crespo-Cuaresma e Wörz foram defasados os efeitos das externalidades em um período $(t-1)$, considerando a hipótese de que não necessariamente o efeito das externalidades das exportações é imediato. Ademais, ambos os modelos foram reestimados, incluindo, além das variáveis explicativas descritas anteriormente, também algumas variáveis dummies de interação. A dummy corresponde aos estados que apresentaram um nível de desenvolvimento muito alto das exportações totais no período de 20092012, (Figura 1 (b)). ${ }^{4}$ Além disso, as interações feitas foram com o diferencial de produtividade e com as externalidades das exportações, isto é, a inclusão visa captar diferenças regionais quanto à importância da inserção externa no crescimento econômico.

\subsubsection{Procedimento de Estimação}

Como estratégia empírica, construiu-se um painel de dados considerando os 26 estados brasileiros e o Distrito Federal, analisando os cinco períodos selecionados. Ao utilizar o painel estático, alguns problemas como o de endogeneidade

metodologia adotada por Cangussu; Salvato e Nakabashi (2010). Além desses autores, Galimberti e Caldart (2010), ao aplicar o modelo de Feder (1983) para alguns municípios do Rio Grande do Sul, também usaram o consumo de energia elétrica industrial como proxy para o capital físico. Ademais, a taxa de crescimento de energia elétrica industrial representa não só a capacidade instalada, bem como o uso efetivo dessa capacidade na economia.

3 Justifica-se que foi agregado o setor de alta intensidade tecnológica com o setor de média alta intensidade tecnológica, tendo em vista que autores como Lamonica e Feijó (2011) defendem que ambos os setores são intensivos em capital e tecnologia, diferenciando-se dos demais grupos. Para os estados classificados com um nível de desenvolvimento elevado das exportações, atribuiu-se o valor igual a "1" correspondendo a: São Paulo, Minas Gerais, Rio de Janeiro, Rio Grande do Sul, Paraná, Pará, Espírito Santo, Mato Grosso, Bahia e Santa Catarina. 
podem surgir. Por isso, Arellano e Bond ( $1991^{5}$ apud CAMERON; TRIVEDI, 2010) apresentam um estimador mais eficiente que pode ser obtido com o uso de instrumentos adicionais, cuja validade está atrelada à condição de ortogonalidade entre os valores da variável dependente e os erros. Dessa forma, os autores propõem um estimador de variáveis instrumentais generalizado, sendo que todos os valores defasados disponíveis da variável dependente e das variáveis pré-determinadas em cada período são instrumentos válidos (Generalized Method of Moments - GMM). Além do mais, pode-se utilizar a primeira diferença dos regressores estritamente exógenos como instrumentos na estimativa.

Dentre o grupo de modelos GMM, dispõe-se de diferentes alternativas. Uma delas é a conhecida Difference GMM, que utiliza modelos em primeiras diferenças com a utilização das variáveis defasadas em pelo menos dois períodos como instrumento. Porém, especialmente quando se utiliza uma série temporal pequena e, portanto, um reduzido número de instrumentos, aconselha-se a utilização de estimadores que incluem defasagens em nível das variáveis usadas como instrumento, denominado de GMM - System. E este foi o estimador utilizado neste trabalho.

Basicamente, Arellano e Bond (1991) derivaram duas versões para os estimadores GMM. A primeira versão faz a suposição de que os termos de erro são independentes e homocedásticos, conhecido como estimador one-step; na segunda versão, two-step, os resíduos gerados na primeira etapa são empregados visando obter uma estimativa consistente da matriz de variância-covariância, relaxando as hipóteses de independência e consistência. Portanto, para estimar (7) e (15) utilizou-se a variante two-step, ressaltando, porém, que como tal estimador pode subestimar os erros-padrão, foi necessário utilizar a correção de Windmeijer (2005), conforme destacado por Cameron e Trivedi (2010).

No que se refere aos problemas econométricos, utilizou-se o teste de Arellano e Bond para a autocorrelação de primeira e segunda ordem em todas as estimativas efetuadas, tendo em vista a característica do painel dinâmico de apresentar uma sensibilidade à autocorrelação dos resíduos. A consistência das estimativas é obtida se a hipótese nula não for estatisticamente próxima de zero, ou seja, rejeita-se a $H_{0}$ em favor da hipótese $H_{a}$ e, dessa forma, há a ausência de autocorrelação de primeira ordem. Por outro lado, a ausência de autocorrelação de segunda ordem ocorre se a hipótese nula for estatisticamente próxima de zero, isto é, aceita-se $H_{0}$ em favor da $H_{a}$.

Ademais, para testar a especificação do modelo e a consistência do estimador GMM, utilizou-se o teste de Sargan/Hansen de sobreidentificação, o qual avalia a validade dos instrumentos utilizados. O teste busca verificar a existência de cor-

5 ARELLANO, M.; BOND, S. Some tests of specification for panel data: Monte Carlo evidence and an application to employment equations. The Review of Economic Studies, v. 58, n. 2, p. 277-297, 1991. 
relação entre os resíduos da regressão e os instrumentos utilizados, tendo a validade dos instrumentos na hipótese nula. (CAMERON; TRIVEDI, 2010).

Por fim, dada a potencialidade de causalidade reversa entre a taxa de crescimento econômico e o capital físico, esta última foi considerada como endógena, de modo que é correlacionada com os erros no presente e no passado. $\mathrm{O}$ mesmo procedimento foi feito para as exportações, considerando-as endógenas. Atrelado a isso, é possível que as externalidades das exportações demorem algum tempo para serem observadas, de maneira que este efeito sobre o crescimento econômico seja evidenciado no médio prazo. Neste sentido, além da relação contemporânea, incluiu-se uma defasagem para esta variável.

\section{Exportações e Crescimento Econômico dos Estados Brasileiros}

O Brasil deu um grande salto na sua inserção internacional nos últimos anos. Diante da estabilização macroeconômica conquistada na década de 1990, aliada à época de ouro do comércio internacional no início do século XXI, com a valorização das commodities agrícolas e minerais, ampliou-se a possibilidade de um maior crescimento para o país. (CUNHA et al., 2011).

É importante destacar que mesmo com a turbulência da crise financeira de 2009 dos mercados internacionais, o Brasil saiu de um montante exportado de aproximadamente US $\$ 32$ bilhões em 1989 para US $\$ 239$ bilhões em 2012 (Gráfico 1), crescendo a uma taxa média anual de 10,07\%. De forma geral, as exportações brasileiras aumentaram expressivamente o seu valor entre 1989 e 2012, proporcionando ao país uma maior inserção internacional.

Gráfico 1 - Evolução das Exportações Totais Brasileiras (em bilhões de US\$ FOB)

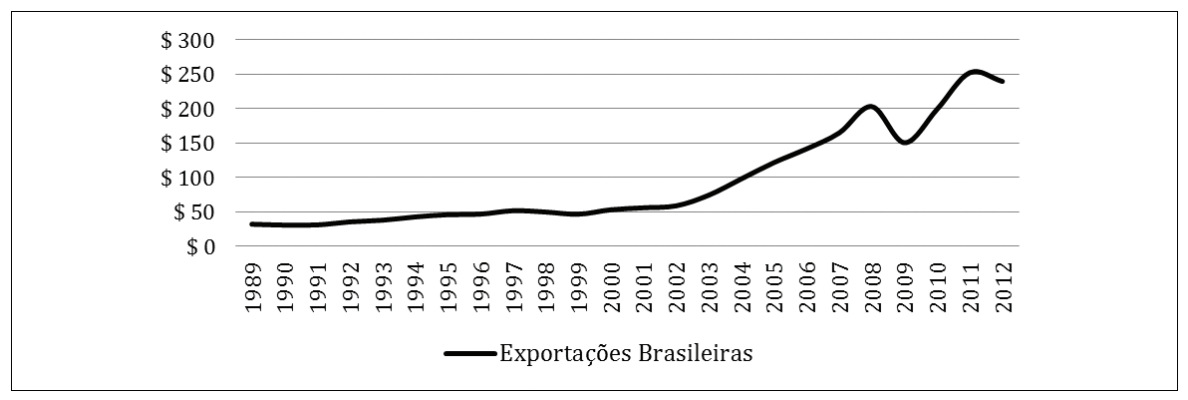

Fonte: Elaboração própria com base nos dados do Ministério do Desenvolvimento, Indústria e Comércio Exterior (BRASIL, 2014).

Em termos de distribuição espacial, Figura 1 (a), observa-se que no período de 1989-1992 tinha-se uma forte concentração e um elevado nível de desenvolvimento das exportações na região Sudeste e em parte do Sul do país. Nove estados 
da federação possuíam uma participação conjunta de 92,62\% de toda inserção internacional brasileira: São Paulo, Minas Gerais, Rio Grande do Sul, Paraná, Rio de Janeiro, Espírito Santo, Santa Catarina, Pará e o estado da Bahia.

Ao analisar 2009-2012, Figura 1 (b), observa-se um aperfeiçoamento na evolução e no nível de desenvolvimento das exportações totais dos estados quando comparado o período inicial, com taxas de crescimento sensivelmente maiores para os estados que menos exportavam inicialmente, conforme a Figura 1 (a). Porém, como o grau de concentração espacial da inserção externa é muito grande no Brasil, essas altas taxas não significaram elevação significativa na participação do comércio internacional, especialmente dos estados localizados nas regiões Norte e Nordeste.

Figura 1 - Evolução das Exportações Totais Brasileiras

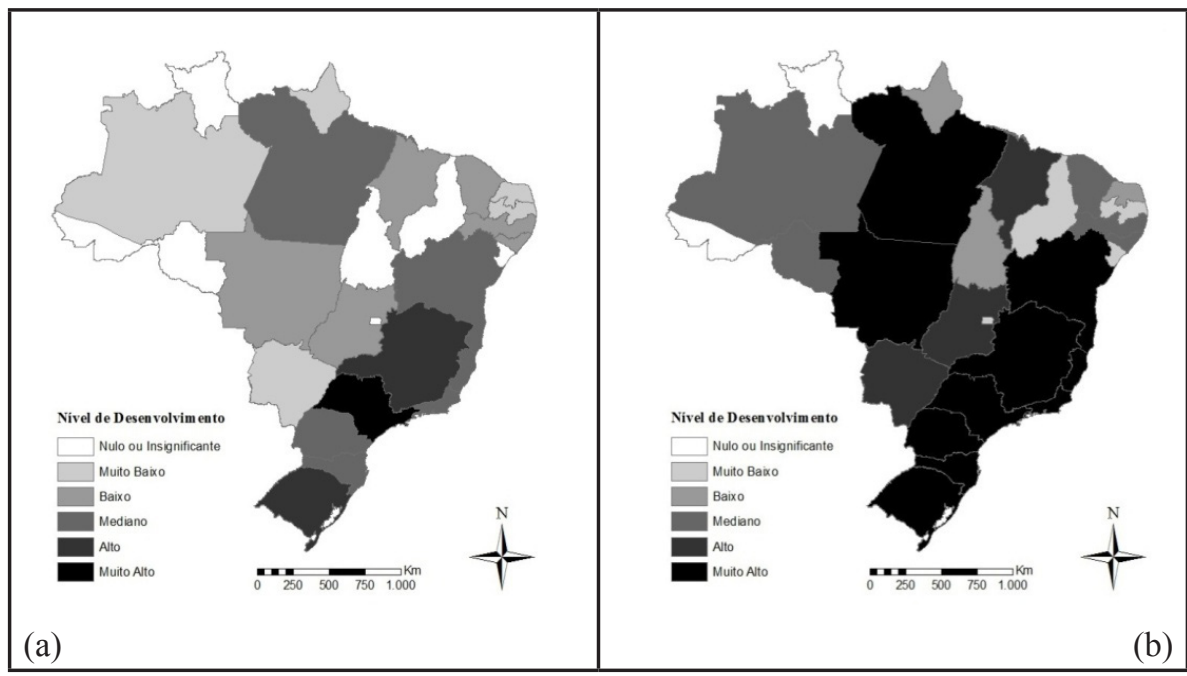




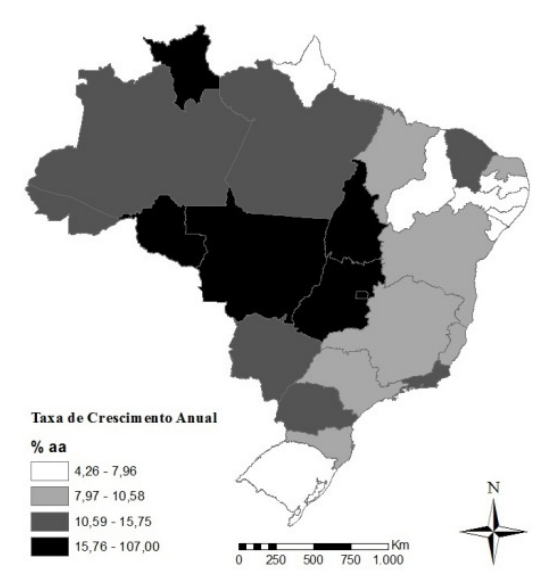

(c)

Fonte: Elaboração própria com base nos dados do Ministério do Desenvolvimento, Indústria e Comércio Exterior (BRASIL, 2014).

Nota: (a) Período de 1989 a 1992 em valores médios (US\$ FOB); (b) Período de 2009 a 2012 em valores médios (US\$ FOB); (c) Taxa de crescimento anual estimada via regressão exponencial. Para os valores da legenda, ver Apêndice A.

Dessa forma, em 2009-2012 as exportações ainda permaneceram concentradas, de tal maneira que apenas treze estados eram responsáveis por 96,81\% dessa inserção: São Paulo, Minas Gerais, Rio de Janeiro, Rio Grande do Sul, Paraná, Pará, Espírito Santo, Mato Grosso, Bahia, Santa Catarina, Goiás, Mato Grosso do Sul e o estado do Maranhão. Assim, se por um lado o comércio internacional do país cresceu grandemente, a sua distribuição ao longo do país teve poucas mudanças, permanecendo altamente centrada especialmente no eixo Sul-Sudeste.

É claro que em termos nacionais, essa inserção maior do país internacionalmente foi importante. No entanto, é necessário também avaliar o comportamento da pauta exportadora brasileira. Neste sentido, subdividindo o comércio internacional em níveis tecnológicos, tem-se uma tendência de crescimento em todos os segmentos (Gráfico 2). Entretanto, em valores absolutos, as exportações brasileiras no período de 2009-2012 ainda eram lideradas, sobretudo, pelos setores menos intensivos em tecnologia (média baixa, baixa, produtos não industriais, média alta e alta tecnologia, respectivamente). 
Gráfico 2 - Evolução das Exportações por Setores de Intensidade Tecnológica (em bilhões de US\$ FOB) - 1989 a 2012

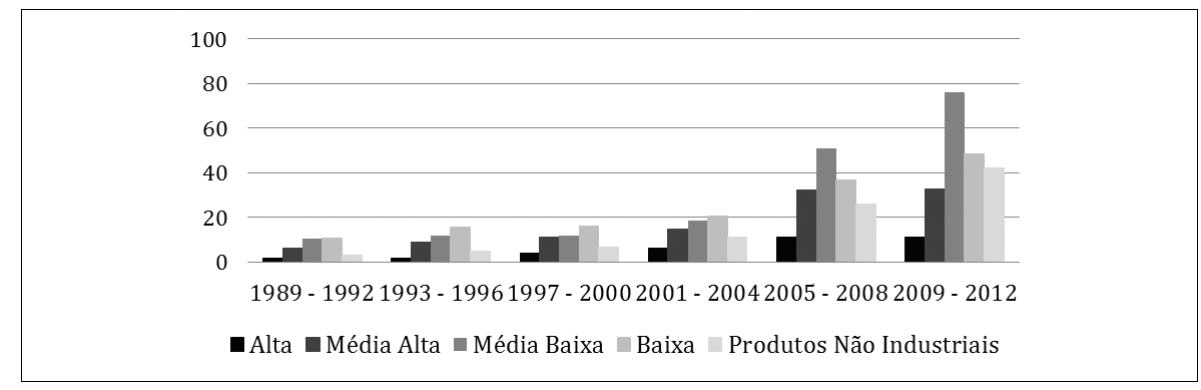

Fonte: Elaboração própria com base nos dados do Ministério do Desenvolvimento, Indústria e Comércio Exterior (BRASIL, 2014).

Em termos de participação (Gráfico 3), a composição da pauta praticamente manteve a mesma estrutura, centrada em segmentos menos intensivos em tecnologia, além de uma maior participação dos produtos não industriais. Juntos, a média baixa, a baixa tecnologia e os produtos não industriais eram responsáveis por 75,14\% das exportações em 1989-1992, elevando-se para 79,23\% em 2009-2012.

Resultado semelhante é apresentado por Cunha et al. (2011), que não apenas identificaram um aumento no total das exportações brasileiras, como também uma importante ampliação na pauta dos produtos primários e intensivos em recursos naturais. Neste sentido, o desafio se finda em assegurar que a primarização da pauta exportadora possa contribuir para um círculo virtuoso de desenvolvimento, com uma estrutura diversificada internacionalmente.

Gráfico 3 - Composição das Exportações Brasileiras por Setores de Intensidade Tecnológica

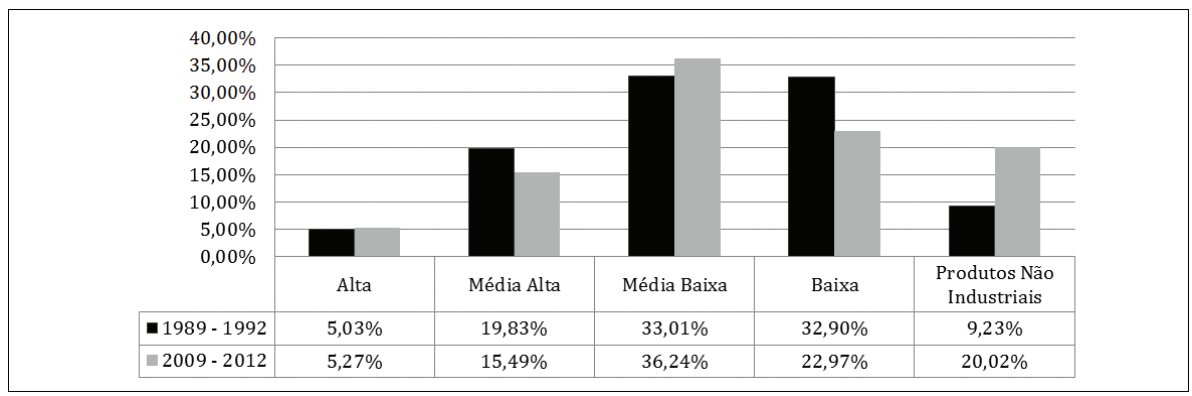

Fonte: Elaboração própria com base nos dados do Ministério do Desenvolvimento, Indústria e Comércio Exterior (BRASIL, 2014). 
$\mathrm{Na}$ análise regional da distribuição espacial de cada segmento que compõe a inserção internacional do país (Figura 2), constata-se a existência de um padrão de distribuição espacial bastante similar, especialmente quando comparado às exportações da alta, média alta, média baixa e baixa tecnologia, abrangendo particularmente o eixo Sul-Sudeste, com raras exceções.

Figura 2 - Evolução e Taxa de Crescimento das Exportações Subdivididas em Níveis Tecnológicos

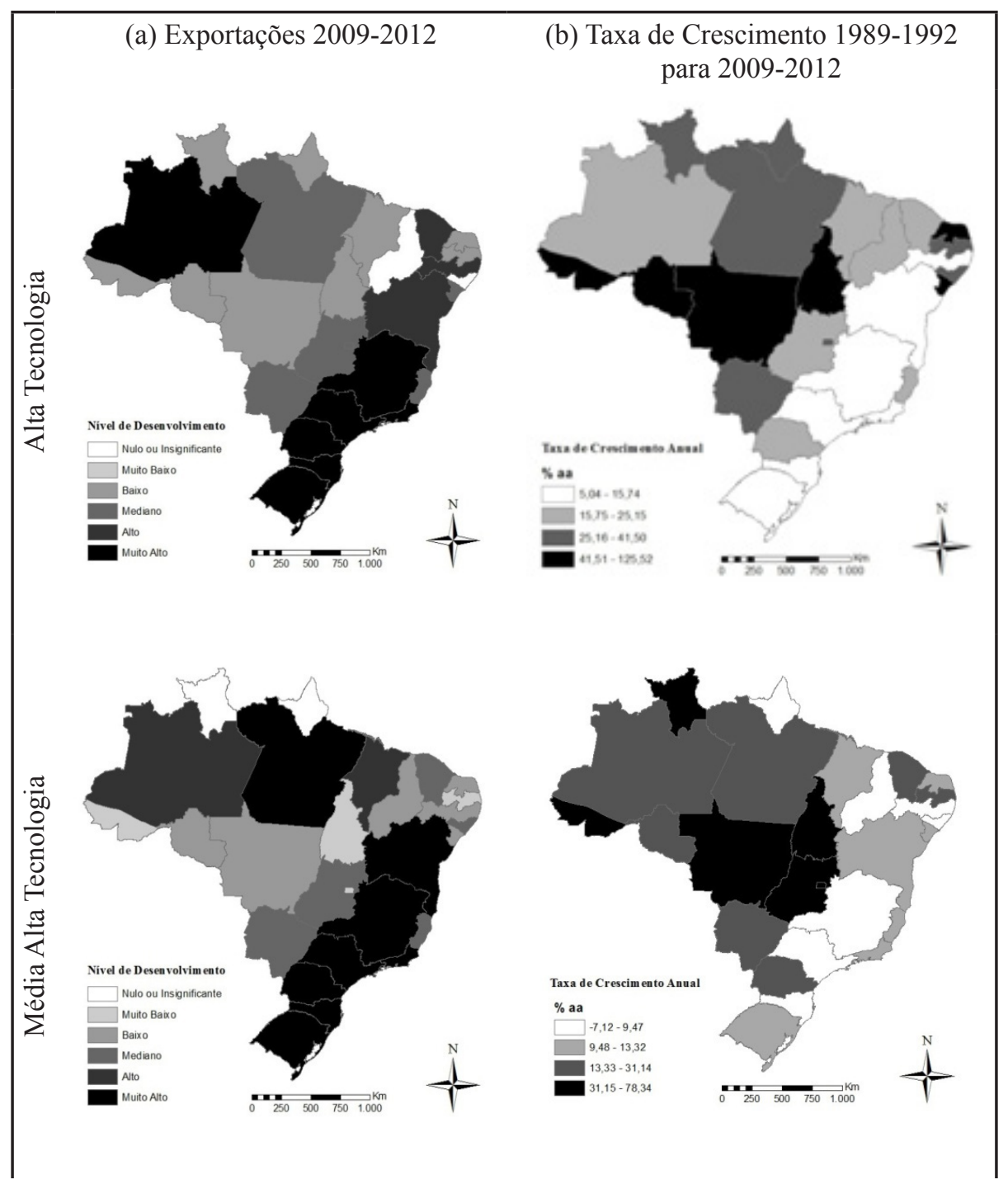




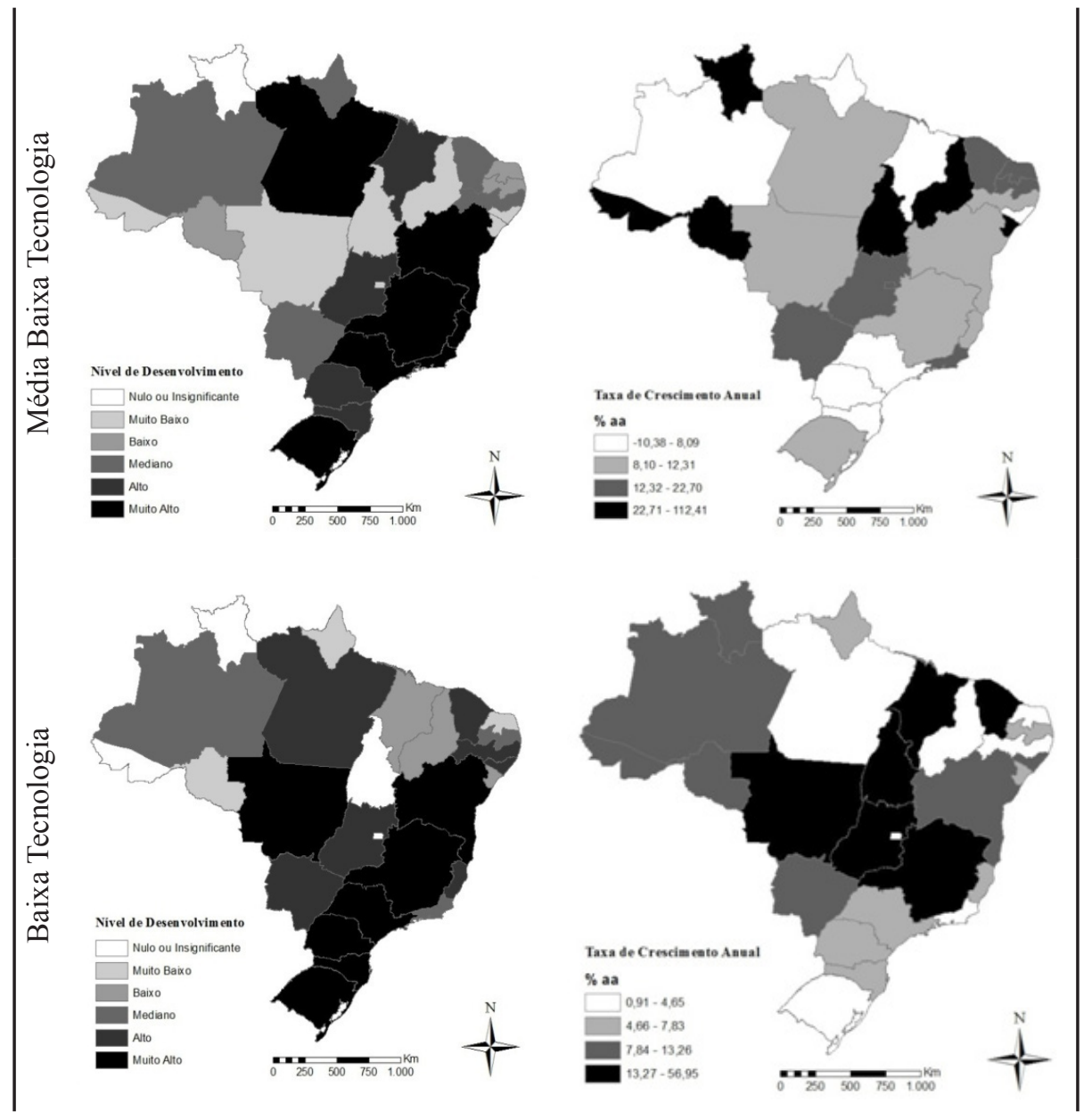




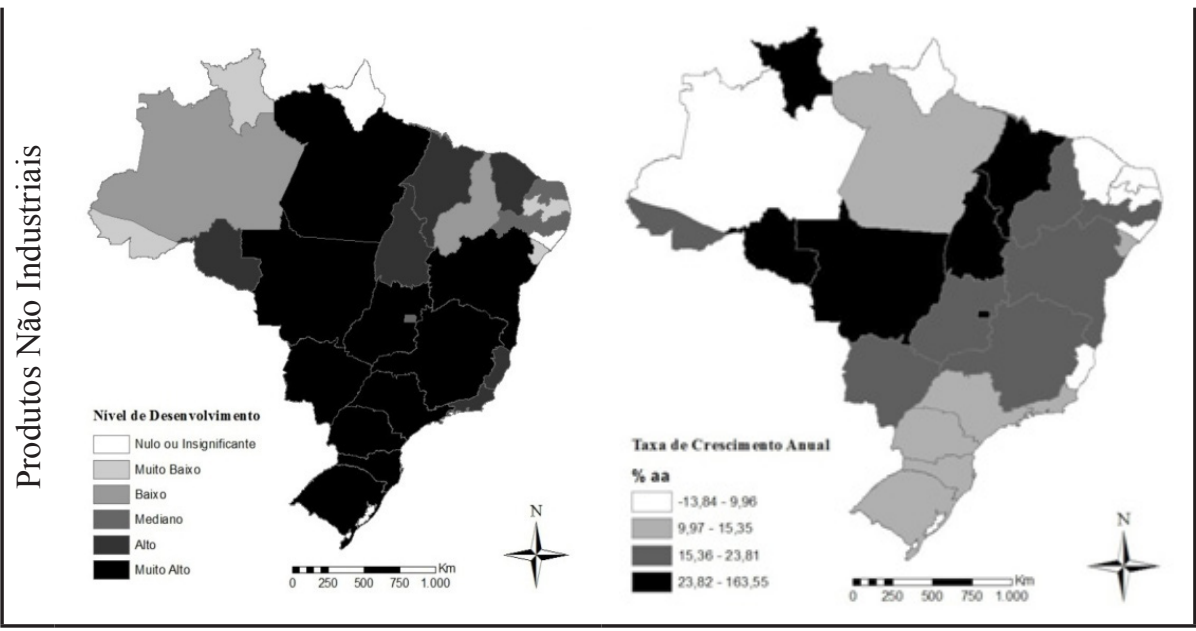

Fonte: Elaboração própria com base nos dados do Ministério do Desenvolvimento, Indústria e Comércio Exterior (BRASIL, 2014).

Nota: Para os valores da legenda, ver Apêndice A.

A distribuição relativa dessas exportações (Tabela 1) é bastante desigual, com poucos espaços sendo responsáveis por boa parte da inserção internacional do país. Um exemplo é São Paulo, que, sozinho, detinha em 2009-2012 a maior fatia dessa inserção: 76\% das exportações da alta tecnologia; 51\% da média alta; $9 \%$ da média baixa e $33 \%$ da baixa tecnologia.

Tabela 1 - Participação Relativa das Exportações por Intensidade Tecnológica (\%)

\begin{tabular}{l|c|c|c|c|c|c|c|c|c|c}
\hline \multirow{2}{*}{ Região } & \multicolumn{3}{|c|}{ Alta } & \multicolumn{2}{c|}{ Média Alta } & \multicolumn{2}{c|}{ Média Baixa } & \multicolumn{2}{c}{ Baixa } & \multicolumn{2}{c}{$\begin{array}{c}\text { Prod. Não } \\
\text { Ind. }\end{array}$} \\
\cline { 2 - 11 } & (a) & (b) & (a) & (b) & (a) & (b) & (a) & (b) & (a) & (b) \\
\hline Norte & 0,93 & 3,05 & 0,91 & 4,99 & 11,64 & 14,57 & 3,82 & 2,24 & 4,84 & 4,83 \\
Nordeste & 1,96 & 0,96 & 6,89 & 7,66 & 10,32 & 6,27 & 10,26 & 12,6 & 6,32 & 5,98 \\
Sul & 5,72 & 12,04 & 13,19 & 23,1 & 5,2 & 4,62 & 43,73 & 29,09 & 33,27 & 32,12 \\
Sudeste & 91,37 & 83,86 & 78,99 & 63,9 & 72,01 & 72,77 & 39,7 & 43,84 & 46,3 & 29,5 \\
$\begin{array}{l}\text { Centro- } \\
\text { Oeste }\end{array}$ & 0,01 & 0,1 & 0 & 0,32 & 0,83 & 1,77 & 2,49 & 12,22 & 9,28 & 27,57 \\
\hline
\end{tabular}

Fonte: Elaboração própria com base nos dados do Ministério do Desenvolvimento, Indústria e Comércio Exterior (BRASIL, 2014).

Nota: (a) Período de 1989 a 1992 em valores médios (US\$ FOB); (b) Período de 2009 a 2012 em valores médios (US\$ FOB). 
Dentre as regiões, o Sudeste é a que mais contribuiu para a inserção internacional do país em quase todos os segmentos analisados. É importante destacar que tal região vem perdendo participação, contudo, ainda possui o maior market share (Tabela 1). Ademais, as perdas de participação do Sudeste beneficiaram, sobretudo, o Sul e/ou o Centro-Oeste, favorecendo timidamente o Norte e o Nordeste. Entretanto, os produtos não industriais apresentaram uma distribuição espacial mais homogênea, tendo uma maior quantidade de estados classificados entre os níveis mais elevados de desenvolvimento das exportações.

Embora na Figura 2 (b) se constate uma melhora de quase todos os estados em praticamente todos os níveis tecnológicos, com taxas de crescimento maiores exatamente em regiões onde a participação na inserção internacional era inicialmente menor, não foi o suficiente para tornar as exportações mais homogêneas ao longo do país. Nesse contexto, observa-se que as regiões Sul e Sudeste representam, independente do segmento exportado, mais de $70 \%$ de todo comércio internacional brasileiro.

\subsection{A Importância das Exportações no Crescimento Econômico dos Estados Brasileiros}

Embora sendo ínfimo o valor exportado por muitos estados brasileiros, houve um crescimento das exportações em todo o território nacional e em praticamente todos os níveis tecnológicos, restando saber se essa inserção no mercado externo contribuiu de alguma maneira para a dinamização das economias estaduais.

Feder (1983) destaca que a ação das exportações pode ser decisiva na geração de renda de uma região. O seu impacto pode ser maior que a simples mudança no seu volume; esses efeitos indiretos podem advir dos ganhos de economia de escala, do aumento das capacidades, dos ganhos de produtividade, da maior variedade de produtos, além de que a inserção internacional pode induzir a pressões competitivas que conduzem a um aumento na atualização tecnológica, dentre outros benefícios. Dessa forma, existe uma tendência de obter, além do efeito direto das exportações no crescimento econômico (por fazer parte do produto agregado), reações indiretas sobre a economia. E são esses efeitos que o modelo de Feder (1983) busca identificar.

No caso dos estados brasileiros, essa relação entre a produtividade, as externalidades das exportações e a taxa de crescimento econômico pode ser visualizada na Tabela 2. Destarte, existe um efeito positivo e significativo (a um nível de significância de $5 \%$ ) das externalidades ( $\mathrm{EXT}_{\mathrm{t}-1}$ ) sobre a dinâmica econômica dos estados, indicando transbordamentos tecnológicos, ganhos quanto à eficiência produtiva e ganhos suficientes para elevar ainda mais o crescimento econômico. Entretanto, esse efeito não é imediato, refletindo no crescimento subsequente do PIB (Tabela 2 - Modelo I). 
Em relação ao diferencial de produtividade (PRD), não foi possível captar nenhuma influência significativa do setor exportador frente ao setor doméstico. Por outro lado, os coeficientes da variável capital físico $(\triangle \mathrm{ENE})$, da população $(\triangle \mathrm{POP})$ e do PIB defasado $\left(\mathrm{PIB}_{\mathrm{t}-1}\right)$ mostraram-se positivos e significativos na determinação do crescimento econômico. Esses resultados e os sinais dos coeficientes se assemelham parcialmente com os obtidos por Feder (1983), o qual evidenciou a existência de externalidades positivas do setor exportador sobre o setor não exportador. No entanto, Feder (1983) também identificou um diferencial de produtividade, fenômeno não verificado no caso dos estados brasileiros.

O modelo (7) foi reestimado (Modelo II) tentando identificar efeitos diferenciados das exportações quando analisados os diferentes espaços brasileiros. Construiu-se uma dummy representativa dos estados que estavam classificados com uma inserção internacional "muito alta" em 2009-2012, Figura 1 (b), procurando testar se os efeitos da inserção externa são mais elevados nestes espaços. Como corolário, reafirmou-se o efeito das externalidades no crescimento econômico estadual. Além disso, naqueles estados que apresentaram níveis elevados na inserção internacional (dummies de interação com as externalidades), o efeito das externalidades é ainda maior, não se processando apenas no período $(t+1)$, mas também no próprio período em que se executam as exportações.

Por terem uma elevada inserção externa, esses estados apresentaram uma competitividade maior que os demais espaços, significando, por exemplo, a presença de uma infraestrutura maior, de aglomerados produtivos, de mão de obra mais especializada, etc. Assim, ao efetivar a venda internacionalmente, esses estados não precisam de um intervalo de tempo para se adaptarem e gerarem externalidades, podendo ter efeitos de produção e de consumo imediato. Ademais, o próprio perfil exportador desses estados, especialmente por apresentarem um maior conteúdo tecnológico em relação aos demais (conforme vislumbrado nas figuras anteriores), tende a gerar imediatamente efeitos superiores de externalidades.

No caso da produtividade, quando se analisa separadamente os estados, percebe-se um diferencial de produtividade para os produtos exportados, especialmente nos espaços com baixa participação no comércio internacional. Nesse sentido, quando esses estados adquirem qualquer diferencial de produtividade, conseguem se inserir internacionalmente. Por outro lado, naqueles estados com uma participação significativa no comércio internacional, o diferencial de produtividade tende a ser menor, justificado pela própria dinâmica produtiva que tende a ser mais intensa, constituindo-se como competitivos tanto os produtos exportados, quanto os destinados ao mercado local. 
Tabela 2 - Resultado das Estimações Econométricas para o Modelo de Feder Estados Brasileiros - 1989 a 2011

\begin{tabular}{|c|c|c|c|}
\hline \multirow{2}{*}{ Variável } & \multicolumn{3}{|c|}{ Modelo Estimado GMM - System (7) } \\
\hline & $\begin{array}{c}\text { Sinal } \\
\text { Esperado }\end{array}$ & Modelo I & Modelo II \\
\hline$\Delta P I B_{t-1}$ & $(+)$ & $0,205(0,00)^{*}$ & $0,18(0,00)^{*}$ \\
\hline$\triangle E N E$ & $(+)$ & $0,105(0,00)^{*}$ & $0,102(0,00)^{*}$ \\
\hline$\triangle P O P$ & $(+)$ & $0,169(0,03)^{*}$ & $0,28(0,006)^{*}$ \\
\hline$P R D$ & $(+)$ & $0,001(0,98)$ & $0,158(0,05)^{*}$ \\
\hline PRD (Dummy) & $(+)$ & - & $-0,18(0,02)^{*}$ \\
\hline$E X T$ & $(+)$ & $0,0007(0,52)$ & $0,0005(0,75)$ \\
\hline$E X T_{t-1}$ & $(+)$ & $0,025(0,00)^{*}$ & $0,002(0,00)^{*}$ \\
\hline EXT (Dummy) & $(+)$ & - & $0,029(0,01)^{*}$ \\
\hline$E X T_{t-1}($ Dummy $)$ & $(+)$ & - & $0,047(0,00)$ \\
\hline Intercepto & & $0,080(0,00)^{*}$ & $0,086(0,00)^{*}$ \\
\hline Teste Sargan/Hansen & & 19,4 & 14,9 \\
\hline AR (1) & & 0,00 & 0,00 \\
\hline $\operatorname{AR}(2)$ & & 0,61 & 0,13 \\
\hline
\end{tabular}

Fonte: Elaboração própria a partir de estimativas dos autores.

Nota: (a) *, denota 5\% de significância; (b) Entre parênteses estão reportados os p-valores, destacando que os erros-padrão das estimativas correspondem aos erros-padrão robustos; (c) Dummy geográfico, corresponde os estados que tiveram uma participação elevada nas exportações do Brasil em 2012 (Figura 1); (d) AR (1) e AR (2) são respectivamente os pvalores das autocorrelações do erro em primeira e segunda ordem; (e) A diferença entre o Modelo I e o Modelo II refere-se às dummies de interação, presentes no Modelo II.

Com esses resultados, percebe-se que as exportações apresentam um efeito que vai além da sua contribuição direta no produto agregado do país, gerando efeitos multiplicadores, desencadeando, dessa forma, um círculo virtuoso para o crescimento econômico que não se restringe ao período atual, propagando-se ao longo do tempo.

Mas será que todos os bens exportados geram os mesmos efeitos? Será que existem diferenças em termos de ganhos quando se considera a agregação de valor dos bens exportados? Crespo-Cuaresma e Wörz (2003) captaram as diferenças e os benefícios das externalidades e da produtividade exatamente quando analisaram as exportações por níveis tecnológicos.

Fazendo essa análise para os estados brasileiros (Tabela 3 - Modelo I), não se conseguiu captar nenhum efeito significativo das externalidades nas exportações menos intensivas em tecnologia (EXTbaixa) e (EXTñind) no período $(t)$ sobre o crescimento do PIB. Somente os bens da indústria de alta tecnologia (EXTalta) apresentaram esses benefícios para o crescimento econômico. Em um segundo momento, este efeito transbordamento ocorre tanto para as exportações dos segmentos de alta $\left(\right.$ EXTalta $\left._{\mathrm{t}-1}\right)$ como também para os segmentos de baixa tecnologia $\left(\right.$ EXTbaixa $\left._{t-1}\right)$. Inclusive, diferentemente de Crespo-Cuaresma e Wörz (2003), o 
efeito das externalidades para os setores de baixa e alta intensidade tecnológica foram não significativos, porém, o efeito das externalidades do setor de produtos não industriais obteve um coeficiente negativo e significativo, mostrando um papel ambíguo na economia.

Assim, não são instantâneos os ganhos em termos de externalidades para os produtos da indústria de baixa tecnologia, mas são ganhos auferidos nos períodos posteriores. Como a indústria de baixa tecnologia tem uma disseminação maior ao longo do país, então nem todos os espaços conseguem imediatamente obter efeitos de produção e de consumo, exatamente por não deterem aspectos regionais atrativos para a sua localização produtiva, obtendo apenas em um segundo momento.

Agora, para os bens mais intensivos em tecnologia, os ganhos são imediatos e também se prorrogam ao longo do tempo. Ora, como a sua produção é concentrada ao longo do território nacional, em espaços que em geral apresentam certa competitividade (infraestrutura robusta, mão de obra especializada, entre outros), então, quando as suas exportações são elevadas e os efeitos multiplicadores não são drenados, justifica-se a influência imediata das externalidades (Tabela 3).

No caso das externalidades dos produtos não industriais (EXTñind) e (EXTñind $_{t-1}$ ), não se conseguiu captar nenhum efeito significativo, isto é, não exerce influência no crescimento econômico estadual via a geração de externalidades. É importante ressaltar que não se está negando o efeito direto que essas exportações apresentam no PIB (por fazer parte da sua composição), porém não foi possível obter efeitos indiretos oriundos de transbordamentos que este setor exportador poderia gerar na economia, ressaltando que esse resultado ocorre quando a estimação considera todos os estados do país (Tabela 3 - Modelo I).

Em relação ao diferencial de produtividade $(P R D)$, nenhum segmento analisado obteve um coeficiente significativo, não sendo possivel captar nenhuma influência da inserção internacional frente ao setor doméstico. E dentre as variáveis de controle, apenas a taxa de crescimento do capital físico $(\triangle E N E)$ continuou a apresentar um efeito positivo e significativo sobre o crescimento do PIB dos estados brasileiros, simultaneamente com a defasagem do PIB $\left(\Delta P B_{t-1}\right)$.

Ao reestimar (15), incluindo dummies de interação entre o espaço e os efeitos das exportações (Tabela 3 - Modelo II), observou-se uma influência maior das externalidades na dinâmica econômica brasileira do que a observada no Modelo I. No caso dos produtos de alta tecnologia (EXTalta), o efeito das externalidades aparece somente para os estados com um nível de exportação relativamente alto, tendo resultados positivos tanto no período $(t)$ como nos períodos subsequentes. ${ }^{6}$

6 Boa parte desse resultado se deve ao próprio perfil das exportações desses estados com um nível elevado de inserção internacional, apresentando um maior conteúdo tecnológico em relação aos demais estados brasileiros. Destarte, para Frankel e Romer (1999), a relação entre os fatores geográficos do comércio e da renda estimulam a acumulação de capital físico e 
Naqueles estados com um nível de exportação mais baixo, os efeitos deixam de ser significativos para a alta tecnologia.

Todavia, quando se analisam os bens da indústria da baixa tecnologia $\left(E\right.$ T.baixa $a_{t-1}$ ) e os produtos não industriais (EXTñind ${ }_{t-1}$ ), os mesmos apresentaram efeitos posteriores em todos os espaços, sem existir diferenciação entre os estados brasileiros. Nesse contexto, reafirma-se o efeito das externalidades na dinâmica econômica, com uma influência para todo o território em se tratando das exportações dos bens menos intensivos em tecnologia, e com um efeito restrito para os bens mais intensivos em tecnologia, exclusivamente para os estados com maior participação externa.

Considerando o diferencial de produtividade, apenas os setores da alta tecnologia (PRDalta) e os setores da baixa tecnologia (PRDbaixa) apresentaram efeitos positivos e significativos. Consequentemente, apenas os grandes estados exportadores possuem ganhos de produtividade para seus bens comercializados no mercado internacional. Para Crespo-Cuaresma e Wörz (2003), o impacto do diferencial de produtividade sobre o crescimento depende da intensidade tecnológica dos respectivos setores da economia, isto é, os ganhos dinâmicos das exportações de alta tecnologia (efeito positivo e significativo), superam o setor de baixa tecnologia (efeito negativo e significativo) reforçando a importância, para um crescimento de longo prazo de um país, em função de uma reestruturação dos setores menos intensivos para setores mais intensivos em tecnologia.

humano, aumentando a produção para determinados níveis de capital, o que se converteria em externalidades, conforme captado pelos coeficientes da Tabela 3. 
Tabela 3 - Resultado das Estimações Econométricas para o Modelo de CrespoCuaresma e Wörz - Estados Brasileiros - 1989 a 2011

\begin{tabular}{|c|c|c|c|}
\hline \multirow{2}{*}{ Variável } & \multicolumn{3}{|c|}{ Modelo Estimado GMM - System (15) } \\
\hline & $\begin{array}{c}\text { Sinal } \\
\text { Esperado }\end{array}$ & Modelo I & Modelo II \\
\hline$\Delta P I B_{t-1}$ & $(+)$ & $0,157(0,00)^{*}$ & $0,084(0,00)^{*}$ \\
\hline$\triangle E N E$ & $(+)$ & $0,146(0,00)^{*}$ & $0,184(0,00)^{*}$ \\
\hline$\triangle P O P$ & $(+)$ & $0,462(0,22)$ & $0,675(0,42)$ \\
\hline PRDalta & $(+)$ & $0,223(0,17)$ & $0,346(0,37)$ \\
\hline PRDalta(Dummy) & $(+)$ & - & $6,49(0,02)^{*}$ \\
\hline PRDbaixa & $(+)$ & $0,47(0,20)$ & $0,23(0,52)$ \\
\hline PRDbaixa (Dummy) & $(+)$ & - & $3,02(0,03)^{*}$ \\
\hline PRDñind & $(+)$ & $0,19(0,14)$ & $0,48(0,19)$ \\
\hline PRDñind (Dummy) & $(+)$ & - & $1,61(0,41)$ \\
\hline EXTalta & $(+)$ & $0,003(0,03)^{*}$ & $0,003(0,28)$ \\
\hline EXT alta $_{t-1}$ & $(+)$ & $0,002(0,00)^{*}$ & $0,0001(0,32)$ \\
\hline EXTalta (Dummy) & $(+)$ & - & $0,02(0,05)^{*}$ \\
\hline EXT alta $_{t-1}($ Dummy $)$ & $(+)$ & - & $0,06(0,03)^{*}$ \\
\hline EXTbaixa & $(+)$ & $0,011(0,12)$ & $0,007(0,59)$ \\
\hline EXT baixa $a_{t-1}$ & $(+)$ & $0,017(0,00)^{*}$ & $0,018(0,00)^{*}$ \\
\hline EXTbaixa (Dummy) & $(+)$ & - & $0,05(0,25)$ \\
\hline EXT baixa $_{t-1}$ (Dummy) & $(+)$ & - & $0,004(0,96)$ \\
\hline EXT ñind & $(+)$ & $0,001(0,10)$ & $0,001(0,58)$ \\
\hline EXT ñind ${ }_{t-1}$ & $(+)$ & $0,0005(0,19)$ & $0,001(0,03)^{*}$ \\
\hline EXTñind (Dummy) & $(+)$ & - & $0,029(0,43)$ \\
\hline EXT ñind t-1 $^{\text {(Dummy })}$ & $(+)$ & - & $0,04(0,19)$ \\
\hline Intercepto & & $0,065(0,01)^{*}$ & $0,086(0,17)$ \\
\hline Teste Sargan/Hansen & & 12,7 & 14,4 \\
\hline $\mathrm{AR}(1)$ & & 0,00 & 0,01 \\
\hline $\mathrm{AR}(2)$ & & 0,60 & 0,27 \\
\hline
\end{tabular}

Fonte: Elaboração própria a partir de estimativas dos autores.

Nota: (a) *, denota 5\% de significância; (b) Entre parênteses estão reportados os p-valores, destacando que os erros-padrão das estimativas correspondem aos erros-padrão robustos; (c) Dummy geográfico, corresponde os estados que tiveram uma participação elevada nas exportações do Brasil em 2012 (Figura 1); (d) AR (1) e AR (2) são respectivamente os pvalores das autocorrelações do erro em primeira e segunda ordem; (e) A diferença entre o Modelo I e o Modelo II refere-se às dummies de interação, presentes no Modelo II.

\section{Considerações Finais}

A identificação de que as exportações podem influenciar o crescimento econômico via as externalidades, especialmente dos bens mais intensivos em tecnologia, é importante no sentido de uma reflexão maior quanto aos rumos do comércio internacional do país. Ora, grande parte das regiões brasileiras agrega pouco valor (em termos de industrialização) aos seus produtos exportados. Com exceção das regiões Sul e Sudeste, as demais concentram parte de seus esforços particularmente na venda de produtos não industrializados. Neste sentido, a constatação de efei- 
tos superiores para os bens mais intensivos em tecnologia (seja via externalidades como produtividade) deduz a necessidade de se repensar em políticas regionais de inserção externa, buscando, em alguma medida, a agregação de valor local a esses produtos.

É evidente que bens mais intensivos em tecnologia não são tão simples de se produzir em todo o território nacional (por demandarem infraestrutura, mão de obra especializada, dentre outros fatores), no entanto, indústrias de baixa tecnologia possuem uma ligação forte com a atividade primária, no qual o Brasil apresenta vantagens competitivas e dispõe de um setor homogeneamente distribuído. Nesse contexto, existe espaço para a ampliação desse tipo de agregação de valor ao longo do país e esta ação revela-se como um potencial caminho para um crescimento econômico mais igualitário no território brasileiro. Entretanto, independente do que se busca exportar, o importante é que existem efeitos indiretos na dinâmica econômica, assim, qualquer ação visando fomentar o comércio internacional resultará em beneficio para a expansão do crescimento econômico.

Por fim, cabe ressaltar que este trabalho se diferencia dos demais estudos aplicados para o Brasil por elaborar uma análise a um nível mais regional, considerando os estados brasileiros. Adicionado a isso, a desagregação das exportações e sua importância no crescimento econômico são elementos diferenciados desta pesquisa. Portanto, os resultados obtidos tornam-se inéditos e importantes tanto para a academia como para os próprios planejadores de políticas públicas, que possuem informações mais pontuais dos elementos que podem trazer um maior dinamismo econômico para os diferentes espaços no país.

\section{Referências}

ALICEWEB. Sistema de Análise das Informações de Comércio Exterior. Dados das exportações brasileiras. Disponível em: <http://aliceweb.mdic.gov.br>. Acesso em: 09 jan. 2014.

ARELLANO, M.; BOND, S. Some tests of specification for data: Monte Carlo evidence and an application to employment equations. The Review of Economic Studies, v. 58, n. 2, p. 277297, Apr. 1991.

BALASSA, B. Exports and economic growth: further evidence. Journal of Development Economics, v. 5, n. 2, p. 181-189, June 1978.

BRASIL. Ministério de Minas e Energia. Empresa de Pesquisa Energética. Anuário estatístico de energia elétrica 2011. Rio de Janeiro, 2011.

Ministério do Desenvolvimento, Indústria e Comércio Exterior. Dados macroeconômicos e regionais. Disponível em: < http://www.mdic.gov.br//sitio>. Acesso em: 05 jan. 2014. 
CAMERON, A. C.; TRIVEDI, P. K. Microeconometrics Using Stata. 2. ed. rev. Texas: Stata Press, 2010.

CÂNDIDO, M. S.; LIMA, F. G. Crescimento econômico e comércio exterior: teoria e evidências para algumas economias asiáticas. Revista de Economia Contemporânea, Rio de Janeiro, v. 14, n. 2, p. 303-325, mai./ago. 2010.

CANGUSSU, R. C.; SALVATO, M. A.; NAKABASHI, L. Uma análise do capital humano sobre o nível de renda dos estados brasileiros: MRW versus Mincer. Estudos Econômicos, São Paulo, v. 40, n. 1, p. 153-183, jan./mar. 2010.

CRESPO-CUARESMA, J.; WÖRZ, J. On export composition and growth. Vienna: University of Vienna, July 2003. (Vienna Economic Papers, n. 0309).

CUNHA, A. M. et al. A intensidade tecnológica das exportações brasileira no ciclo recente de alta nos preços das commodities. Indicadores Econômicos FEE, Porto Alegre, v. 39, n. 3, p. 47-70, 2011.

FEDER, G. On exports and economic growth. Journal of Development Economics, v. 12, n. 1, p. 59-73, Feb./Apr. 1983.

FRANKEL, J. A.; ROMER, D. Does trade cause growth? American Economic Review, v. 89, n. 3, p. 379-399, June 1999.

FURTADO, A. T.; CARVALHO, R. Q. Padrões de intensidade tecnológica da indústria brasileira: um estudo comparativo com os países centrais. São Paulo em Perspectiva, São Paulo, v. 19, n. 1, p. 70-84, jan./mar. 2005.

GALIMBERTI, J. K. Composição das exportações e crescimento econômico: o Brasil no período 1989-2005. In: INSTITUTO DE PESQUISA ECONÔMICA APLICADA. (Org.). Prêmio IPEA-CAIXA-2007: monografias premiadas. Brasília, DF: Ipea, 2008. p. 495-542.

GALIMBERTI, J. K.; CALDART, W. L. As exportações e o crescimento econômico: análise dos municípios do Corede Serra 1997-04. Ensaio FEE, Porto Alegre, v. 31, n. 1, p. 87-112, ago. 2010.

GIAMBIAGI, F. et al. (Org.). Economia brasileira contemporânea: 1945-2010. 2. ed. Rio de Janeiro: Elsevier, 2011.

HERZER, D.; NOWAK-LEHMANN, F. D. Export diversification, externalities and growth. Goettingen: University of Goettingen, 2004. (Discussion Papers, n. 99).

IBRAHIM, I. On exports and economic growth. Jurnal Pengurusan, v. 21, p. 3-18, 2002.

IPEADATA. Dados macroeconômicos e regionais. Disponível em: <http://www.ipeadata.gov. br>. Acesso em: 9 jan. 2014.

IRWIN, D. A.; TERVIÖ, M. Does trade raise income? Evidence from the Twentieth Century. Journal of International Economics, v. 58, n. 1, p. 1-18, 2002. 
JAYME JR., F. G. Comércio internacional e crescimento econômico: o comércio afeta o desenvolvimento? Revista Brasileira de Comércio Exterior, Rio de Janeiro, v. 15, n. 69, p. 6973, 2001.

LAMONICA, M. T.; FEIJÓ, C. A. Crescimento e industrialização no Brasil: uma interpretação à luz das propostas de Kaldor. Revista de Economia Política, v. 31, n. 1, p. 118-138, jan./mar. 2011.

PEROBELLI, F. S.; HADDAD, E. A. Exportações internacionais e interações regionais: uma análise de equilíbrio geral. Estudos Econômicos, São Paulo, v. 36, n. 4, p. 833-866, out./dez. 2006.

PINHEIRO, A. C. O crescimento da produtividade total dos fatores e a estratégia de promoção de exportações: uma revisão da evidência internacional. Pesquisa e Planejamento Econômico, Rio de Janeiro, v. 22, n. 1, p. 1-34, abr. 1992.

RAMOS, P. N. Does the trade balance really matter for regions? The Annals of Regional Science, v. 41, n. 1, p. 229-243, Mar. 2007.

RICARDO, D. Princípios de economia política e tributação. São Paulo: Abril Cultural, 1982.

SOUKIAZIS, E.; ANTUNES, M. Is foreign trade import for regional growth? Empirical evidence from Portugal. Economic Modelling, v. 28, n. 3, p. 1363-1373, May 2011.

WINDMEIJER, F. A finite sample correction for the variance of linear efficient two-step GMM estimators. Journals of Econometrics, Netherlands, v. 126, n. 1, p. 25-51, May 2005. 


\section{Apêndice A - Legendas e Limites dos Mapas das Exportações (US \$ FOB)}

\begin{tabular}{|c|c|c|c|}
\hline Desenvolvimento & Exportações Totais & Alta Tecnologia & Média Alta Tecnologia \\
\hline Muito Baixo & $36.982 .890-211.148 .594$ & $2.222-43.642$ & $79.778-1.252 .817$ \\
\hline Baixo & $211.148 .594-451.593 .825$ & $43.642-479.510$ & $1.252 .817-12.403 .724$ \\
\hline Mediano & $451.593 .825-1.975 .108 .791$ & $479.510-15.168 .067$ & $12.403 .724-77.256 .959$ \\
\hline \multirow[t]{2}{*}{ Muito Alto } & $6.822 .320 .495-53.479 .386 .479$ & $118.206 .128-8.663 .183 .979$ & $879.650 .916-16.590 .623 .078$ \\
\hline & Média Baixa Tecnologia & Baixa Tecnologia & Prod. Não Industriais \\
\hline Nulo/Insignificante & $0-411.950$ & $0-11.646 .060$ & $0-1.367 .799$ \\
\hline Muito Baixo & $411.950-7.161 .021$ & $11.646 .060-62.072 .076$ & $1.367 .799-15.881 .036$ \\
\hline Muito Alto & $1.562 .763 .216-20.101 .151 .990$ & $1.383 .554 .364-15.984 .424 .148$ & $941.378 .369-7.239 .536 .377$ \\
\hline
\end{tabular}

Fonte: Elaboração própria com base nos dados do Ministério do Desenvolvimento, Indústria e Comércio Exterior (BRASIL, 2014).

Nota: (a) Usou-se o software ArcMap 10.2.2 para a construção de mapas e legendas; (b) Para cada tipo de exportação (classificado em níveis tecnológicos), os valores (US\$ FOB) foram organizados por estados e pelas médias anuais, considerando seis períodos (1989 a 1992; 1993 a 1996; 1997 a 2000; 2001 a 2004; 2005 a 2008 e 2009 a 2011) e por fim, tabulados em ordem crescente. Ao mesmo tempo, os respectivos valores foram então segmentados e hierarquizados proporcionalmente em níveis de desenvolvimento (nulo/insignificante, muito baixo, baixo, mediano, alto e muito alto) com o intuito de se vislumbrar efetivamente o processo de evolução e composição das exportações de cada estado por intensidade tecnológica. É importante destacar que o a classificação dos intervalos de cada nível tecnológico considerou a amplitude (maior e menor valor entre 1989 e 2012) ponderada pelo número de classes que se pré-determinou (seis).

Recebido em: 30/09/2015. Aceito em: 04/01/2017. 